\title{
Proposal of data source and method for creating 3D models of buildings
}

\author{
Piotr Cichociński, Damian Jurczyszyn, Monika Kochan \\ AGH University of Science and Technology, al. Mickiewicza 30, 30-059 Kraków, Poland
}

\begin{abstract}
The main objective of this research was to investigate how oblique imagery can be used to create simple models of buildings. Necessary data for this purpose may be acquired during field surveys, but not all details (in particular the roof) can be seen from the ground level. On the other hand, vertical aerial photos and high-resolution satellite images are not able to present the walls of buildings. Therefore, oblique photos might be a compromise. Such pictures show not only the shape but also the relationships between buildings and their surroundings. Oblique photos can be seen on Google Maps and Bing Maps. But none of them can be legitimately used for community projects like OpenStreetMap (OSM), aimed at creating editable and available without restriction map of the world. Instead, in case of hilly and mountainous areas, taking pictures from points high enough to allow good observation of the area of interest can also be considered sufficient source of such information instead of aerial oblique photos. On that basis the height of buildings, their colors and layout and color of roofs can be determined. The results of the research show, that it is possible to use oblique photographs to construct simplified models of buildings, which satisfy the requirements set by simple 3D buildings schema prepared by OSM developers.
\end{abstract}

Keywords: oblique imagery; OpenStreetMap; roof shape.

\section{Introduction}

The first phase of replacing traditional paper maps, plans and atlases with their digital counterparts was to build mapping portals that provide digital images of maps. Two of the most developed include Google Maps and Bing Maps. They use technology that allows selecting desired part and smooth zooming. In addition to viewing maps they also provide some analytical capabilities such as finding a location by name or finding the optimal route. They are also enriched with the possibility of replacing traditional cartographic presentation by aerial photograph or satellite image. OpenStreetMap was created as an alternative to these commercial projects [1] - a community project aimed at creating editable and available without restriction map of the world. Such a map is created based on data from handheld GPS, aerial photographs and other available data sources, as well as sketches made in the field. The project was created because most of the maps, which are generally considered free, actually have legal or technical restrictions on their use. Data to be added to the base of OpenStreetMap database should be correct, verifiable and cannot be subject to copyright or the person entering the data must have full rights to them.

It can be assumed that this step has been completed. Using the increasing performance of computer hardware and speed of Internet connections the possibility to view three-dimensional model of the Earth could be offered to users. Google and Microsoft are still leaders here, providing Google Earth and Virtual Earth software, respectively. However, it seems that the end of capabilities in this area has not been reached. One could suspect that a restriction in access to these capabilities is the need to install additional software. However, web browsers available immediately on any operating system on any device: desktop, smartphone, tablet, are currently universal means of delivering content. Technology, which is designed to enable the presentation of three-dimensional content in browsers, is called WebGL [2].

However, technical capability of transfer and display of 3D data is not enough. Suitable data to offer are necessary. Large corporations build appropriate databases for several years [3]. Developers of OpenStreetMap, as a free alternative in this field, also take certain actions. They agreed upon unified subset of tags on the 3D buildings [4]. These tags include height depicting distance between the lowest possible position with ground contact and the top of the roof of the building and catalog of well-known roof types.

Corresponding author: Piotr Cichociński. E-mail address: Piotr.Cichocinski@agh.edu.pl

http://dx.doi.org/10.3846/enviro.2014.199

(C) 2014 The Authors. Published by VGTU Press. This is an open-access article distributed under the terms of the Creative Commons Attribution License, which permits unrestricted use, distribution, and reproduction in any medium, provided the original author and source are credited. 
Such data may be acquired during field surveys, but not all of the details (in particular the roof) can be seen from the ground level. On the other hand, vertical aerial photos and high-resolution satellite images are not able to present the walls of the building. Therefore, oblique photos might be a compromise [5]. Such picture shows not only the shape but also the relationship between building and its surroundings. Additionally our knowledge and experience often allows accurately interpreting even less clear images.

Oblique photos can be seen on Google Maps and Bing Maps (Bird's Eye View). But none of them can be legitimately used for the OpenStreetMap [6]. Hence, the idea of the application of low-altitude images (taken from heights below 200 meters) from Crewless Air Vehicles (CAV), equipped with a small, lightweight digital camera with a resolution providing the required accuracy for specific purposes, particularly for quick geo-information update of small areas by photogrammetric methods [7]. In case of hilly and mountainous areas taking pictures from points high enough to allow a good observation of the area of interest can also be considered. The latter approach was used in research presented in this paper.

\section{Research objectives}

The main objective of this research was to investigate how oblique imagery can be used to create simple models of buildings. As a by-product a three-dimensional model of reality was created. It was not about the creation of simple cubes, but rather models quite accurately representing shapes of buildings, constructed on the basis of oblique aerial photographs and high-resolution satellite images available in the mapping portals. Most frequently created three-dimensional building models are made using CAD solid modeling abilities (as opposed to GIS capabilities allowing only for so called 2.5D), leading to accurately reproduced shapes of buildings. Textures are then overlaid on them to reflect their actual appearance. However, this case is limited to schematic presentation of buildings, which consists of determining the approximate height, color of the walls, and shape and color of the roof. It was decided to use SketchUp to create models of buildings. This software is provided free of charge and is easy to use.

Creation of 3D map consists of several stages. The first one is the completion of spatial data sources which may be, for example, cadastral maps. 3D model containing information about reality must consist of objects that are representatives of two types. The first type consists of real objects, such as a building, which have clearly defined boundaries and relationships to other objects. The second type consists of all elements, which have not well-defined boundaries and relationships with other objects - Digital Elevation Model (DEM) belongs to this category. Either data that allow generating terrain model are necessary, or ready models can be used. SRTM model is available for the entire Earth, which comes in a horizontal resolution of 3 arc seconds and has required vertical accuracy of about 16 meters [8].

The next step is to model 3D objects on the selected area. In the process of creating 3D objects specialized software from outside GIS, such as AutoCAD, MicroStation or SketchUp are the most commonly used. In order to maximize the faithful representation of the selected area it is necessary to collect available background information on land cover and prepare the texture for 3D objects. The documentation includes, among others, images, iconography and descriptive materials.

The final stage is to visualize 3D maps. For this purpose, all the collected material is used. It is not always possible to reconstruct all elements of land cover. In such cases it is possible to use library of symbols, textures and fills provided by specialized software.

\section{The software and data used}

SketchUp software (currently offered by Trimble) allows the user to create, modify and share three-dimensional models. It is powerful, but also easy-to-use application which allows easy creation of three-dimensional models that can be used in computer-aided design processes in three dimensions.

Modeling in SketchUp is based on linear objects. The combination of three or more lines that lie in the same plane forms a closed geometrical figure. Depending on one's needs, the program allows to create precise or less precise objects. The process of creating realistic models is supported by mechanisms of geometric analysis. This allows locating selected characteristic points of the model, which result from the position of the other points, and displaying tooltips. There are three types of dependencies:

- punctual, based on the exact location of the cursor in the model area,

- linear, based on lines or directions in space,

- planar, which is based on planes in space [9].

Dxf file that contained the outlines of buildings located in the small town Zabierzów, located near Kraków in southern Poland was the basis for practical activities. In addition, shapefiles depicting roads and terrain model were used. Pictures of the Zabierzów area taken with Sony Alpha DSLR-A900 digital single lens camera played the role of oblique photos. 


\section{Description of performed work}

\subsection{Data preparation}

The first stage was carried out in Quantum GIS, which was used because it had OpenLayers plugin for displaying maps provided by Google Maps and Bing Maps. Possessed information about contours and buildings was verified and necessary updates were made using this additional information. As an aside, a comparison of accuracy and detail of the available aerial photographs was made.

The close-ups (Fig. 1) allow noticing the difference in resolution and the age of images. Photos from Bing are more up to date, present newly built houses, but these images are of poor resolution, so at too high magnification it is hard to distinguish the house from the ground. On the other hand, images from Google Maps were made before the photos from Bing, and therefore do not include newly built houses. However, they have much higher resolution, which allows for high magnification without loss of detail.

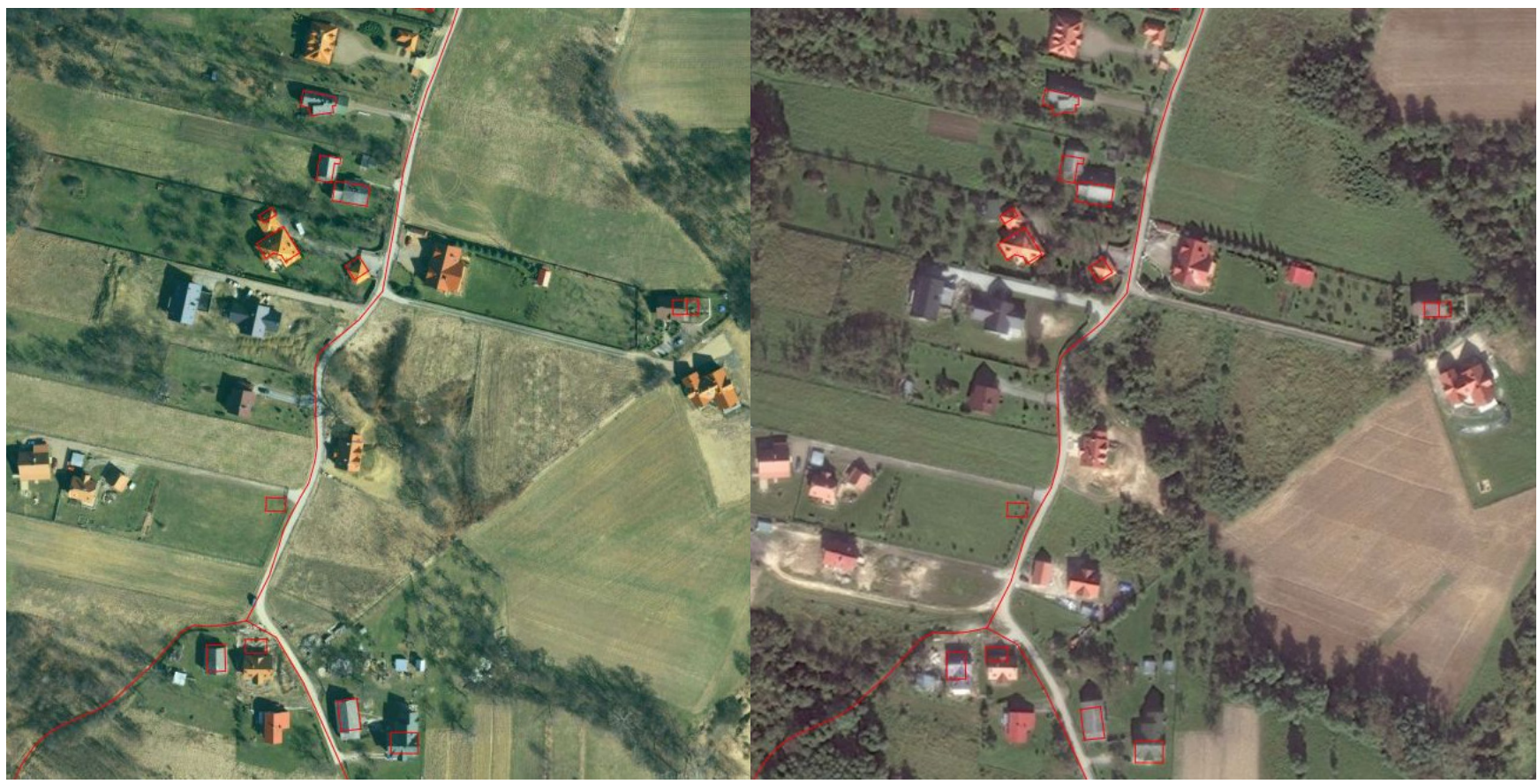

Fig. 1. Comparison of Google Maps (left) and Bing Maps (right)

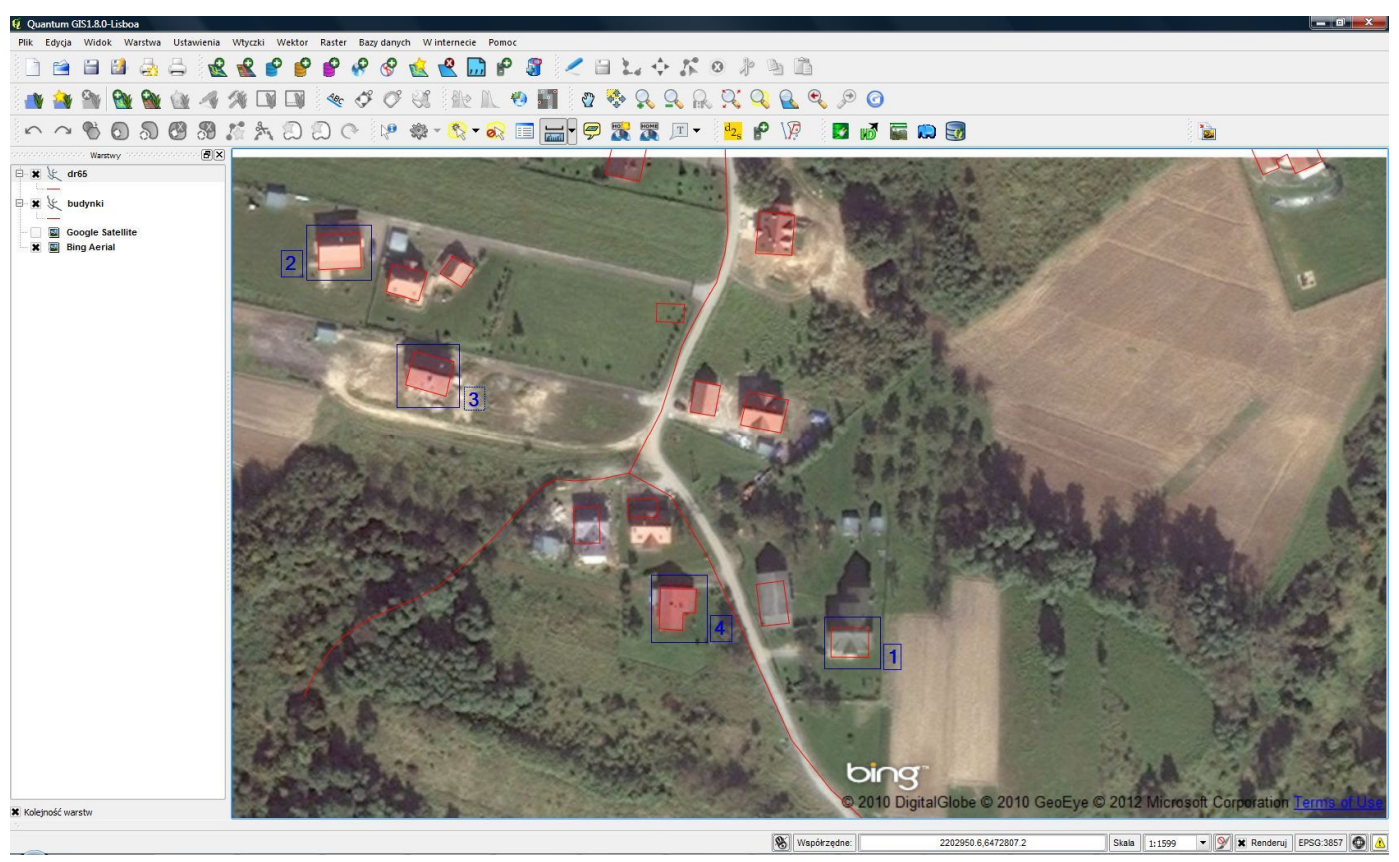

Fig. 2. Numbered buildings on Bing photo 


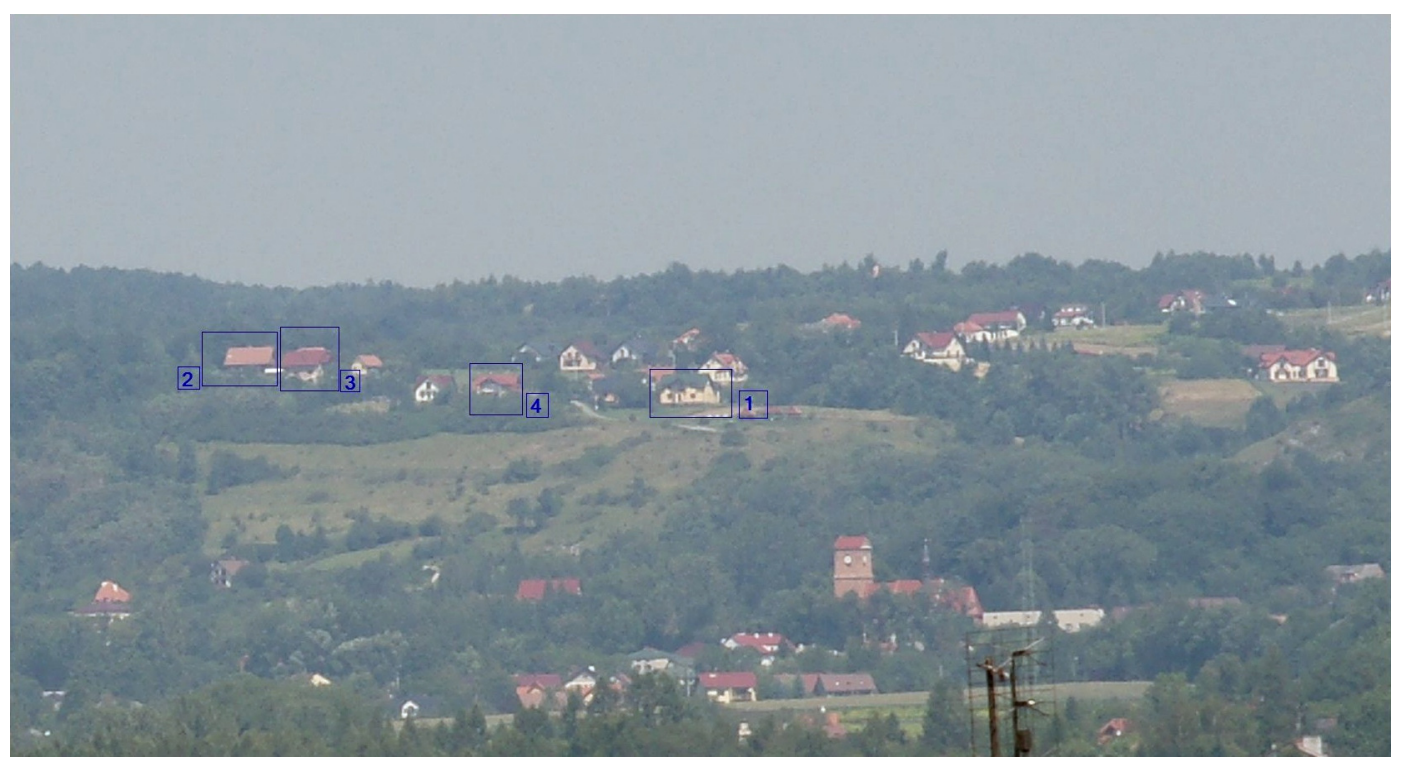

Fig. 3. Buildings identified on the oblique photo

After checking and completing all missing features, buildings layer was exported to dxf file that can be used in SketchUp.

The identification of corresponding buildings in oblique photographs taken was next important step. Comparison was made with aerial photos from Google or Bing portals. Figures 2 and 3 present the same buildings marked on Bing photo and on photo taken, respectively. On that basis, it was possible to determine the height of buildings, their colors and layout and color of roofs.

\subsection{Construction of building models}

Outlines of buildings were loaded using the capabilities of SketchUp to import various data, including CAD formats (dwg, $\mathrm{dxf}$ ). As the outlines of buildings were not treated by the program as surfaces, but as a simple lines, in the first step it was necessary to create surfaces from closed lines (Fig. 4).

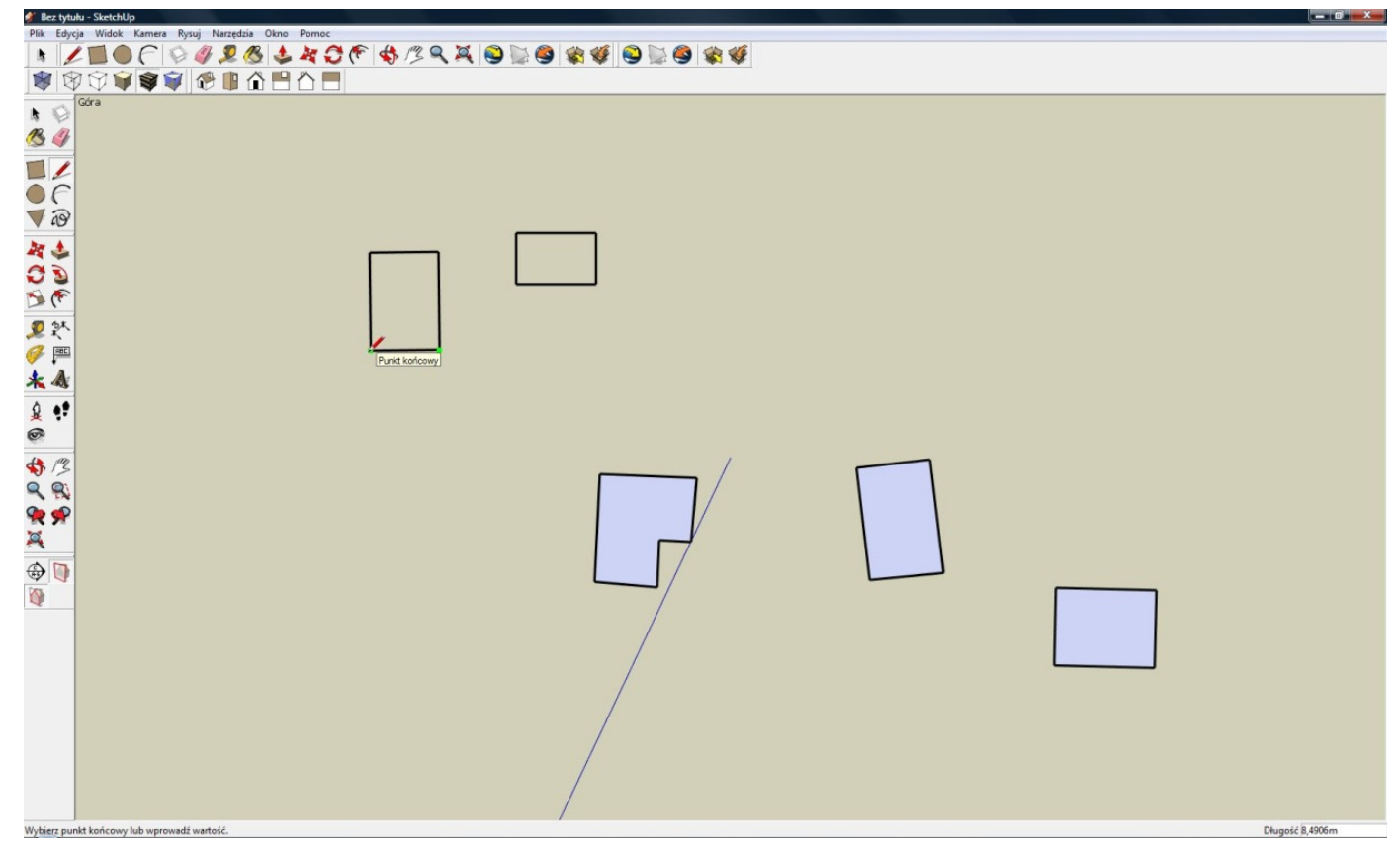

Fig. 4. Buildings in SketchUp as outlines and surfaces

For simplicity the height of one floor was assumed as 3 meters, usable attic at the highest point 4 meters, the roof at the highest point 3 meters. Simple buildings can be created in a very easy way. Use the Push/Pull Tools and then click on the previously created area of the building and move the mouse to indicate the direction in which the surface is to be pulled or pushed, then use the keyboard to enter the height of the building (Fig. 5). 
To create the roof of the house, add the line dividing the solid in half. Select Move/Copy Tool and move the cursor along the line. When the red square changes to green (which means that the cursor is at the midpoint of the line), "pull" up the plane with the mouse. Of course desired height can also be entered using keyboard. To create a symmetrical roof it is important to "pull" along the blue axis (Fig. 6).

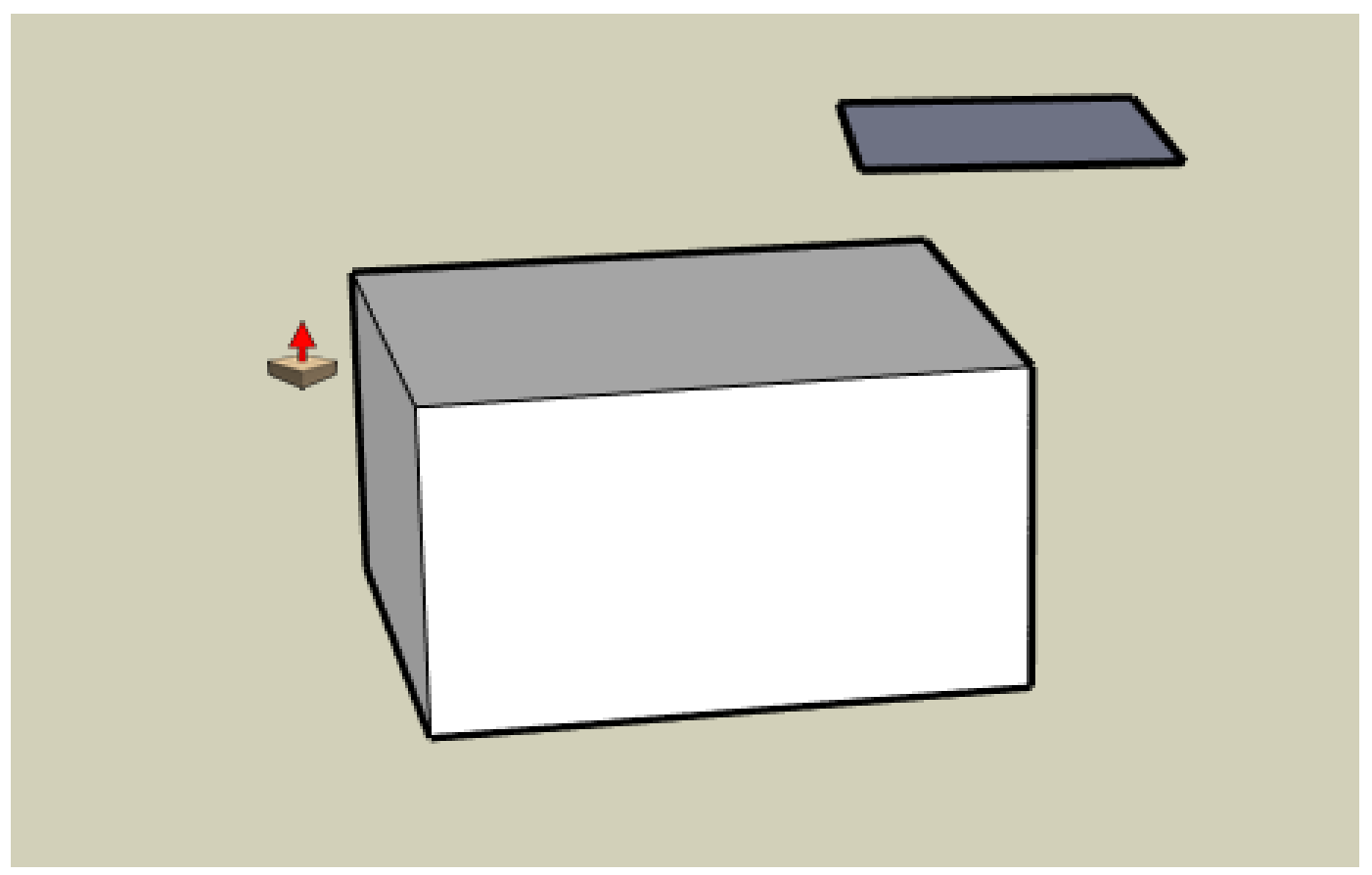

Fig. 5. "Pulling" surface to create a solid

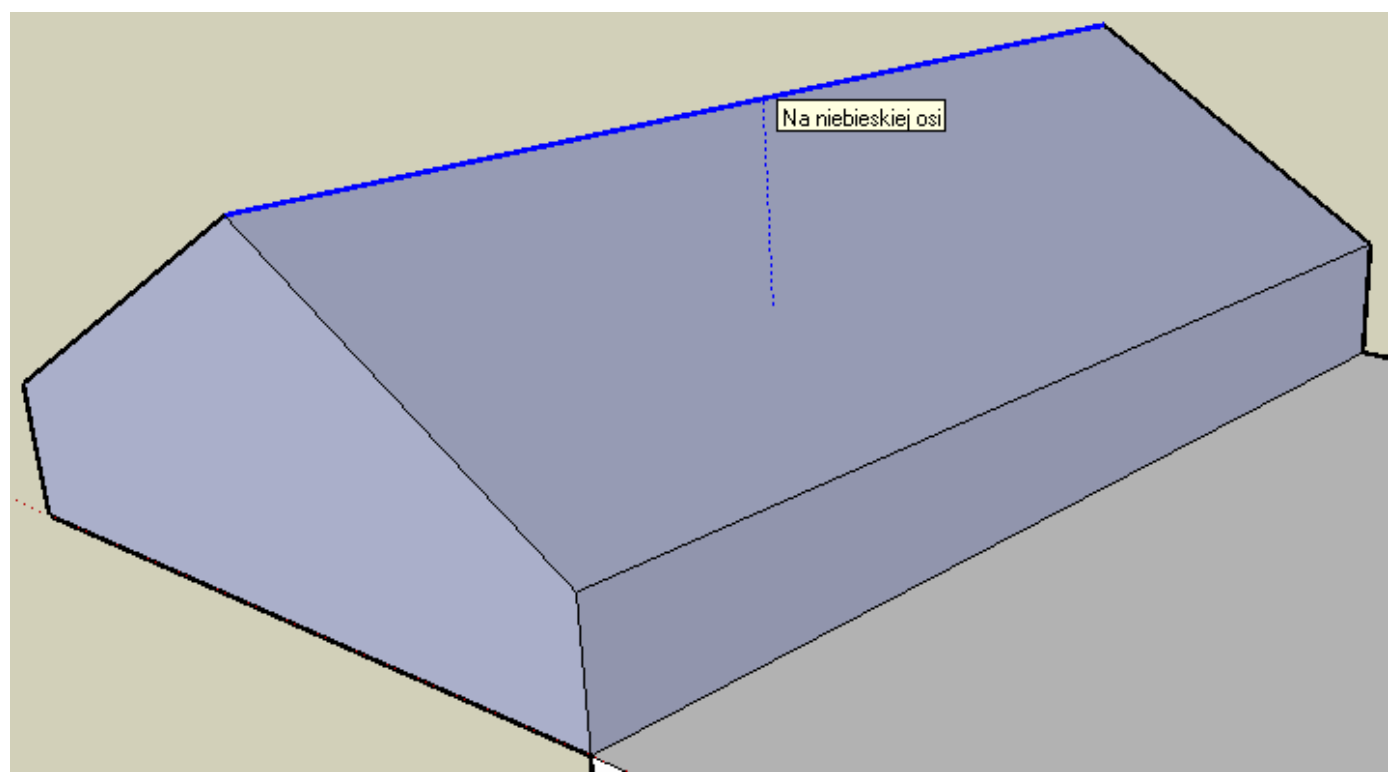

Fig. 6. Model of a roof

Figure 7 shows a part of resulting buildings. Each of the prepared building was saved to a newly created, separate SketchUp file. This was done by copying subsequent buildings and then pasting them, preferably at the point of origin. In case of more buildings location of them should be remembered. To facilitate further actions buildings were numbered and saved under those names in SketchUp files. 


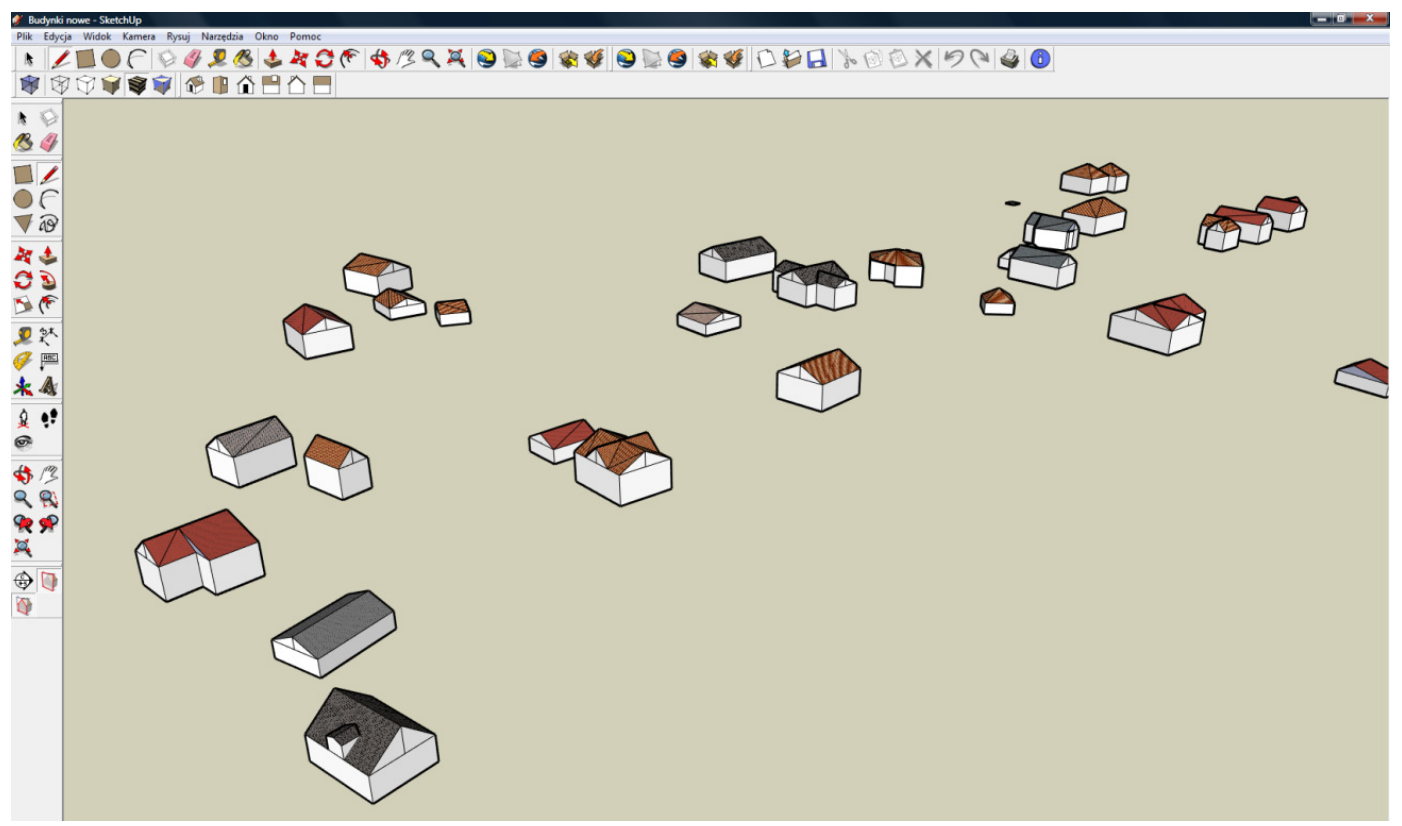

Fig. 7. A part of resulting buildings

\subsection{Visualization}

The last phase of the work was carried out in ArcGIS software. The has the ability to use local 3D models, such as a SketchUp file, to symbolize a point as a 3D object inside ArcScene.

First, a data set of point objects representing individual buildings was created. This was done manually, although it was possible to use a function to generate centroids. Numbers corresponding to the numbers given to individual buildings were assigned to these points. A sketch with the numbering of buildings can be useful, in order to properly locate the position of every building.

Point symbolization was the next step. First, all points were drawn using unique values, based on an attribute containing building number. Then, three-dimensional symbol was assigned to every point: 3D Marker Symbol option was selected from the Type drop down menu in Symbol Property Editor window (Fig. 8) and then the model of the building corresponding to the given point was chosen from the list. Its rotation and size could be changed as required (Fig. 9).

Finally, aerial photo was overlaid on terrain model and models of trees were added for a complete visual effect (Fig. 10).

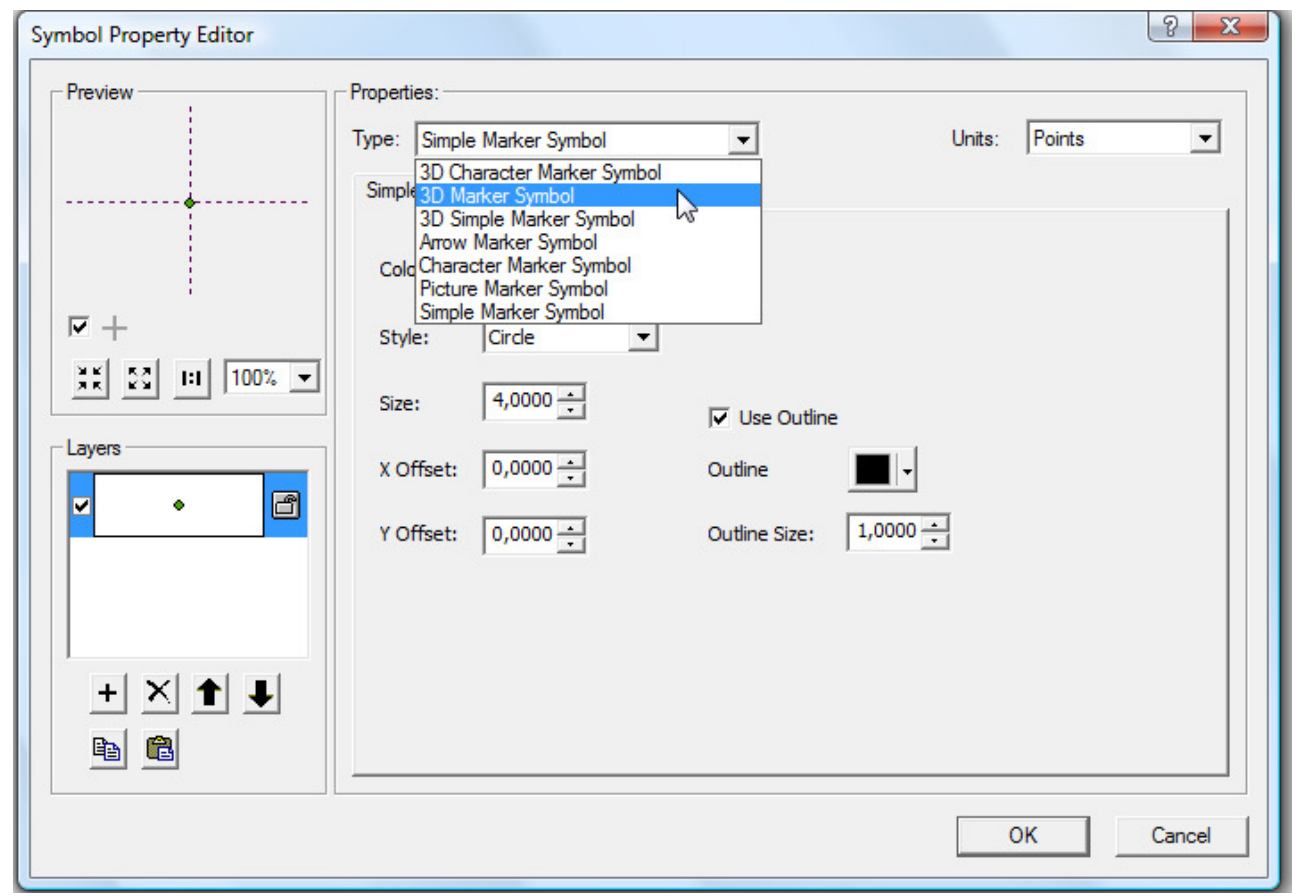

Fig. 8. Symbol Property Editor 


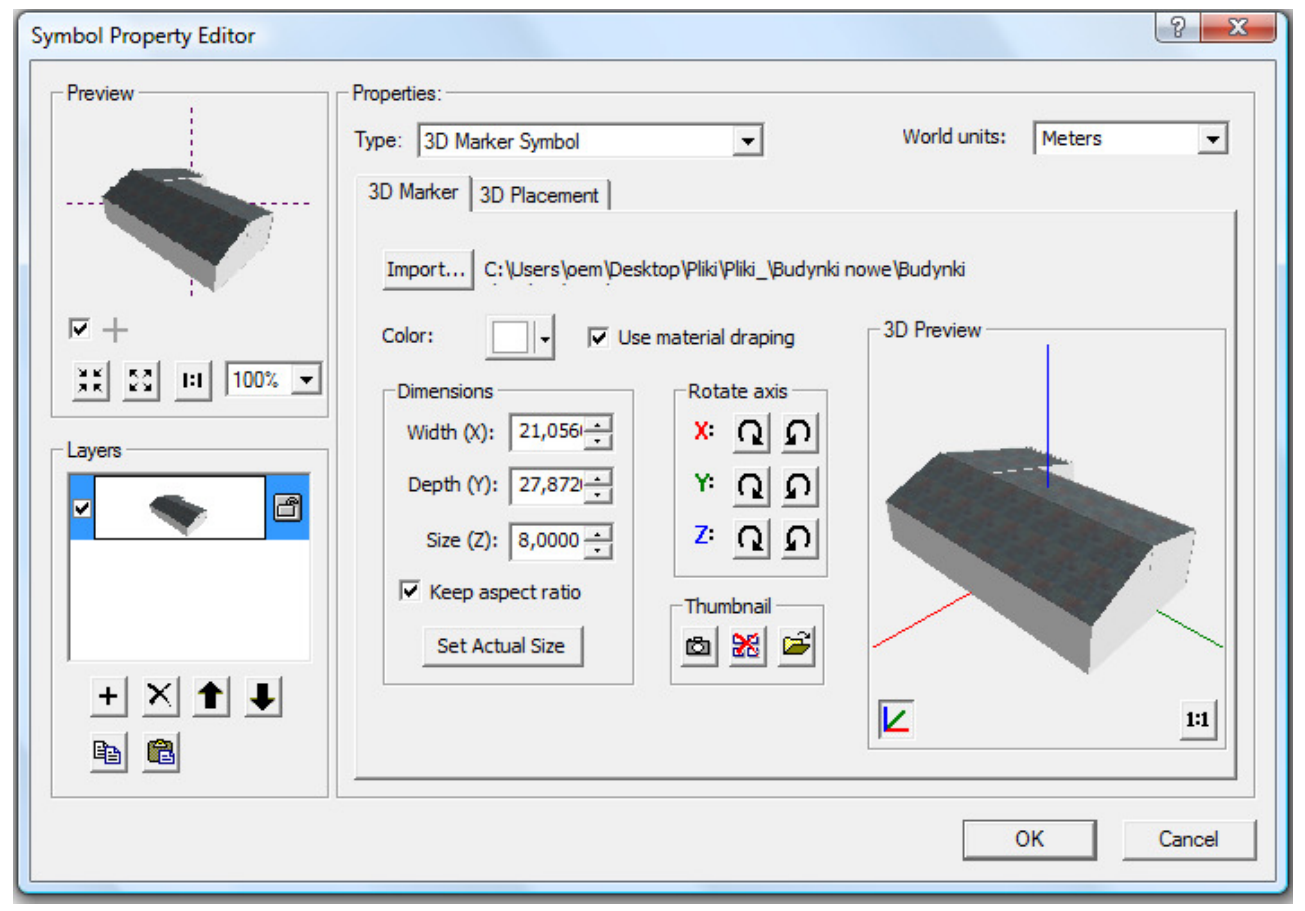

Fig. 9. 3D marker symbol properties

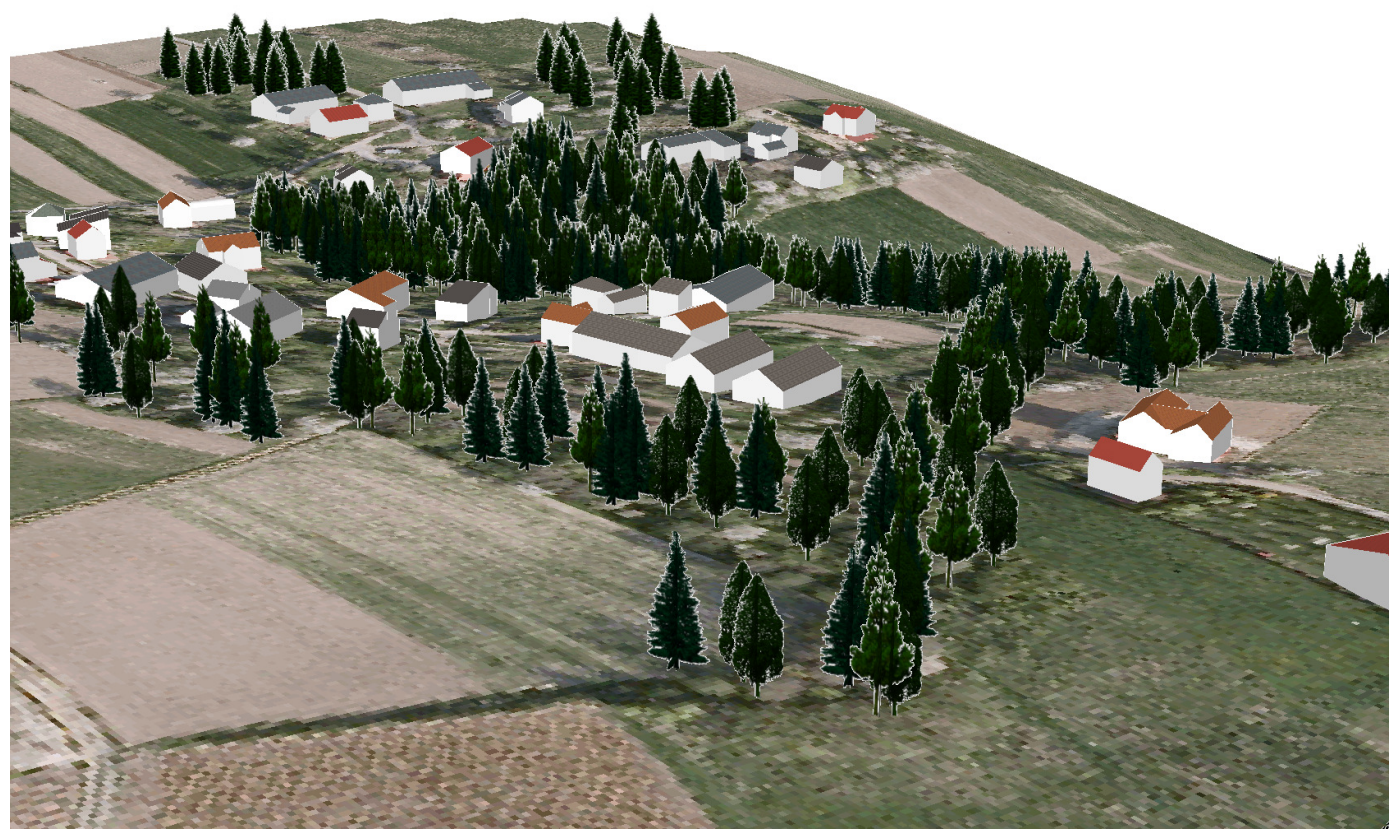

Fig. 10. Final visualization

\section{Conclusions}

The example presented in this paper shows that it is possible to use oblique photographs to construct simplified models of buildings. It fits the currently valid development concept of the OpenStreetMap, which at the present stage of development in the field of 3D provides only basic tags describing the most important features of the buildings, including extremely simplified information on the shape of the roof. However, even such simple models, but taking into account the shape of the roof definitely give better results than polygon features extruded vertically to create boxes.

SketchUp can be recommended to anyone willing to create three-dimensional models of buildings. It is very intuitive and easy to use, allowing creation of three-dimensional models that better reflect reality. Its good cooperation with GIS software enables preparation of more advanced visualizations. 


\section{Acknowledgements}

This work has been done as a part of scientific research carried out in Department of Geomatics.

\section{References}

[1] Haklay, M.; Weber, P. 2008. OpenStreetMap: User-Generated Street Maps, IEEE Pervasive Computing October-December : 12-18. http://dx.doi.org/10.1109/MPRV.2008.80

[2] Khronos Group 2013. WebGL Specification. Version 1.0.2, 01 March 2013. https://www.khronos.org/registry/webgl/specs/1.0/

[3] Różycki, S. 2007. Trójwymiarowe modele miast - tworzenie i zastosowanie [3D city models - generation and applications], Archiwum Fotogrametrii, Kartografii i Teledetekcji [Archives of Photogrammetry, Cartography and Remote Sensing] 17b: 709-716.

[4] OpenStreetMap Wiki 2013. Simple 3D Buildings [cited 30 January 2014]. Available from Internet: http://wiki.openstreetmap.org/wiki/Simple 3D Buildings

[5] Karbo, N.; Schroth, R. 2009. Oblique Aerial Photography: A Status Review, in D. Fritsch (Ed.). Photogrammetric Week `09, $119-125$.

[6] Microsoft 2010. Bing maps imagerty service editor application API's terms of use, Last Updated: November 2010. Available from Internet: http://wiki.openstreetmap.org/w/images/d/d8/Bing_license.pdf

[7] Jankowicz, B. 2010. Fotogrametryczne niskopułapowe naloty platform autonomicznych [CAV photogrammetric low-altitude flights], Infrastruktura i Ekologia Terenów Wiejskich [Infrastructure and Ecology of Rural Areas] (3): 95-101.

[8] Karwel, K.; Ewiak, I. 2008. Estimation of the accuracy of the SRTM terrain model on the area of Poland, The International Archives of the Photogrammetry, Remote Sensing and Spatial Information Sciences 37(B7): 169-172.

[9] Oszczak, B.; Tanajewski, D.; Hermaciński, A.; Klimczuk, M. 2011. Modelowanie trójwymiarowe budynków lotniska Dajtki-Olsztyn w aplikacjach AutoCAD Civil 3D i Google SketchUp [3D modeling of buildings at the Dajtki-Olsztyn airport in AutoCAD Civil 3D and Google SketchUp applications], Roczniki Geomatyki [Annals of Geomatics] 9(4): 29-137. 